\title{
HUBUNGAN STATUS GIZI DAN OLAHRAGA DENGAN KEJADIAN DISMENORE
}

\author{
Rizky Putri Lona, Lela Hartini, Eliana \\ Politeknik Kesehatan Kementerian Kesehatan Bengkulu, Jurusan Kebidanan, \\ Jalan Indragiri Nomor 03 Padang Harapan Kota Bengkulu \\ rizkyputrilona@gmail.com
}

\begin{abstract}
ABSTRAC : As much as 60\% - 95\% women of reproductive ages had. Dysmenorrhea that it caused loss of employment, interfere learning activities at the school and family life. As much as $57,8 \%$ of schoolgirl in SMA I had dysmenorrhea. Many factors that caused of dysmenorrhea, such as nutritional status and exercise habits. Aims of this research were to find out relationship between nutritional status and exercise habits with dysmenorrhea to the schoolgirl in MAN I of Bengkulu City. This research used cross sectional design. Population were all schoolgirl in MAN I of Bengkulu City in 2012. Total of samples were 211 responden, it taken with simple random sampling. The data analyzed univariate and bivariate. Results of research showed that most of schoolgirl had dysmenorrhea $(57,8 \%)$, schoolgirl had abnormal of nutritional status $(42,7 \%)$, schoolgirl had less of exercise habits $(37,4 \%)$. Result of bivariate showed that there was relationship between nutriotional status and exercise habits with incident of dysmenorrhea $(p=0,000)$
\end{abstract}

Keywords : Nutritional status, exercise, Dysmenorrhea

\begin{abstract}
ABSTRAK : Sebanyak 60\%-95\% wanita usia reproduksi mengalami dismenore yang menyebabkan hilangnya kesempatan kerja, mengganggu kegiatan belajar di sekolah dan kehidupan keluarga. Siswi di MAN 1 sebanyak 57,8\% mengalami dismenore. Banyak faktor penyebab dimenore diantaranya adalah status gizi dan kebiasaan olahraga. penelitian ini bertujuan untuk mengetahui hubungan status gizi dan kebiasaan olahraga dengan Dismenore pada Siswi MAN 1 Kota Bengkulu. Penelitian ini menggunakan desain Potong silang. Populasinya adalah seluruh Siswi MAN 1 Kota Bengkulu Tahun 2012. Jumlah sampel 211 responden diambil dengan teknik simpel random sampling. Data dianalisis secara univariat dan bivariat. Hasil penelitian menunjukan sebagian besar $(57,8 \%)$ siswi mengalami dismenore, status gizi tidak normal (42,7\%), kebiasaan olahraga kurang $(37,4 \%)$. Hasil bivariat menunjukan ada hubungan status gizi dan olahraga dengan kejadian dismenore $(\rho=0,000)$.
\end{abstract}

Kata Kunci : Status Gizi, Olahraga, Dismenore.

Penduduk dunia yang berusia dibawah 25 tahun sebesar 6,1 miliyar dan lebih dari 1 miliyar penduduk berusia antara 10-19 tahun. Di Indonesia sendiri saat ini jumlah remaja adalah sekitar sembilan belas peren (19\%) dari total populasi dengan kuantitas 65 juta orang. Remaja merupakan sebagai periode transisi perkembangan dari masa kanakkanak sampai dengan dewasa yang terbagi antara masa remaja awal usia 10-12 tahun, masa remaja pertengahan usia 13-15tahun, masa remaja akhir usia 16-19 tahun (Kristina, 2010). Masa remaja pada perempuan akan terjadi perubahan pada fisik maupun psikologis. Salah satu tanda keremajaan secara biologi yaitu ketika memasuki masa menstruasi (Lilies, 2008).

Setiap wanita memiliki pengalaman menstruasi yang berbeda-beda. Sebagian wanita mendapatkan menstruasi tanpa keluhan, namun tidak sedikit dari mereka yang mendapatkan menstruasi disertai keluhan sehingga mengakibatkan rasa ketidaknyamanan seperti rasa sakit, kram pada pinggang sampai perut bagian bawah yang terjadi saat dan menjelang menstruasi yang sering disebut dengan dismenore (nyeri haid) (Manuaba, 2002 ).

Angka kejadian dismenore dunia sangat besar rata-rata lebih dari 60-93\% perempuan disetiap negara mengalami dismenore yang 
menyebabkan hilangnya kesempatan kerja, mengganggu kegiatan belajar di sekolah dan kehidupan keluarga, dan hanya 1-2\% wanita yang berobat ke tenaga kesehatan. Di Amerika angka kejadian dismenore diperkirakan 45-95\% (Qittun, 2008).

Berdasarkan hasil penelitian dari Indian $J$ (2008) prevalensi kejadian dismenore adalah $73,83 \%$ terdiri dari $6,32 \%$ berat, $30,37 \%$ sedang, 63,29\% ringan. Di Indonesia adalah sebesar $64,25 \%$ terdiri dari $54,89 \%$ dismenore primer, 9,36\% dismenore sekunder (Qittiun, 2008). Dismenore mempunyai risiko yang tinggi pada wanita nulipara, haid memanjang, riwayat keluarga, merokok, mengkonsumsi alkohol (Laurel, 2006).

Pengaturan pola makan untuk mendapatkan status gizi yang baik dan olahraga teratur merupakan hal yang disarankan oleh para ahli untuk mengatasi keluhan dismenore. Menurut Fujiwara et al (2007) berat badan kurang, rendah lemak dan rendah asupan kalori akan mengakibatkan terganggunya konsentrasi hormon ovarium dalam siklus menstruasi yang dapat menimbulkan gangguan menstruasi yaitu dismenore.

Dismenore ini bisa juga disebabkan oleh kurangnya aktifitas olahraga. Menurut Gannon, et al (2000) menunjukan bahwa dismenore lebih rendah pada wanita yang teratur melakukan olahraga dibandingkan wanita yang kurang melakukan kegiatan olahraga.

Hasil wawancara dari 18 siswa MAN 1 yang mengalami dismenore sebanyak 11 siswi dismenore ringan, 5 siswi dismenore sedang dan 2 siswi dismenore berat. Status gizinya terdiri dari sebanyak 9 siswi status gizi kurang, 4 siswi status gizi baik, 5 siswi status gizi lebih. Sedangkan aktivitas olahraga terdiri dari sebanyak 11 siswi mengatakan mereka tidak menyukai kegiatan olahraga dengan alasan membuat badan menjadi berkeringat, kulit menjadi hitam, betis menjadi besar, wajah berminyak serta terpaksa melakukannya pada saat ada pelajaran olahraga untuk mendapatkan nilai. Sehingga peneliti tertarik untuk melakukan penelitian tentang hubungan status gizi dan kebiasaan olahraga dengan dismenore pada Siswi MAN 1 Kota Bengkulu.

\section{BAHAN DAN CARA KERJA}

Penelitian ini adalah penelitian survei analitik dengan desain penelitian potong silang, dimana peneliti melakukan observasi atau pengukuran dua variabel dalam waktu yang sama, yaitu variabel bebas (dismenore) dan dua variabel terikat (status gizi dan olahraga).

Populasi yang diteliti dalam penelitian ini adalah siswi Madrasah Aliyah Negeri 1 Kota Bengkulu Tahun 2012 yaitu 444 siswi. Besar sampel sebanyak 211 siswi yang dibagi menjadi tiga kelas yaitu kelas X, XI, dan kelas XII. Pengambilan sampel dalam penelitian ini menggunakan teknik acak sederhana dengan cara diundi melalui absen kelas. Pengolahan data dilakukan secara univariat, bivariat, dan multivariat.

\section{HASIL}

\section{Analisis univariat}

Dari tabel 1 diketahui bahwa sebagian besar $(57,8 \%)$ siswi mengalami dismenore, hampir sebagian $(42,7 \%)$ siswi status gizi tidak normal, dan hampir sebagian $(37,4 \%)$ siswi dengan kebiasaan olahraga kurang.

Tabel 1 Distribusi Frekuensi Dismenore, Status Gizi Dan Olahraga Siswi MAN 1 Kota Bengkulu Tahun 2012.

\begin{tabular}{lcc}
\hline \multicolumn{1}{c}{ Variabel } & $\begin{array}{c}\text { Frekuensi } \\
(\mathbf{n = 2 1 1})\end{array}$ & $\begin{array}{c}\text { Presentase } \\
(\boldsymbol{\%})\end{array}$ \\
\hline Dismenore & & \\
Iya & 122 & 57,8 \\
Tidak & 89 & 42,2 \\
Status Gizi & & \\
Tidak Normal & 90 & 42,7 \\
Normal & 121 & 57,3 \\
Olahraga & & \\
Kurang & 79 & 37,4 \\
Baik & 132 & 62,6 \\
\hline
\end{tabular}

\section{Analisis bivariat}

Analisis ini dilakukan untuk mengetahui hubungan variabel bebas dan variabel terikat menggunakan uji statistik Chi-quadrat dengan interval kemaknaan (IK) 95\% dan tingkat signifikansi $(\alpha)=0,05$. Hasil analisa bivariat dapat dilihat pada tabel 2. 
Dari Tabel 2 diketahui bahwa hampir seluruh $(76,7 \%)$ siswi dengan status gizi tidak normal mengalami dismenore. Sebaliknya siswi status gizi normal hampir sebagian kecil $(43,8 \%)$ mengalami dismenore. Hasil uji statistik diperoleh $\rho=0,000<\alpha=0,05$, disimpulkan bahwa ada hubungan yang bermakna antara status gizi siswi dengan kejadian dismenore. Siswi yang status gizi tidak normal mempunyai peluang 4,2 kali mengalami dismenore dibandingkan dengan siswi status gizi normal $(\mathrm{OR}=4,216)$.

Tabel 2 Hasil Analisis Hubungan Status Gizi dan Olahraga Dengan Dismenore Pada Siswi MAN 1 Kota Bengkulu Tahun 2012.

\begin{tabular}{|c|c|c|c|c|c|c|c|}
\hline \multirow{3}{*}{$\begin{array}{c}\text { Varia- } \\
\text { bel }\end{array}$} & \multicolumn{4}{|c|}{ Dismenore } & \multirow{3}{*}{$p$} & \multirow{3}{*}{ OR } & \multirow{3}{*}{ IK $95 \%$} \\
\hline & \multicolumn{2}{|c|}{$\begin{array}{c}\text { Disme- } \\
\text { nore }\end{array}$} & \multicolumn{2}{|c|}{$\begin{array}{c}\text { Tidak } \\
\text { Disme- } \\
\text { nore } \\
\end{array}$} & & & \\
\hline & $\mathbf{F}$ & $\%$ & $\mathbf{F}$ & $\%$ & & & \\
\hline \multicolumn{5}{|c|}{ Status Gizi } & \multirow{4}{*}{0,000} & \multirow{4}{*}{4,216} & \multirow{3}{*}{$2,29-7,73$} \\
\hline $\begin{array}{l}\text { Tidak } \\
\text { Normal }\end{array}$ & 69 & 76,7 & 21 & 23,3 & & & \\
\hline Normal & 53 & 43,8 & 68 & 56,2 & & & \\
\hline \multicolumn{5}{|c|}{ Kebiasaan Olah-raga } & & & \\
\hline Kurang & 71 & 89,9 & 8 & 10,1 & \multirow[b]{2}{*}{0,000} & \multirow[b]{2}{*}{14,096} & \multirow[b]{2}{*}{$6,26-31,7$} \\
\hline Baik & 51 & 38,6 & 81 & 61,4 & & & \\
\hline
\end{tabular}

Tabel 2 juga menunjukan bahwa hampir seluruh $(89,9 \%)$ siswi yang kebiasaan olahraga kurang mengalami dismenore. Sebaliknya siswi yang kebiasaan olahraga baik hampir sebagian kecil $(38,6 \%)$ mengalami dismenore. Hasil uji statistik diperoleh $\rho=0,000$ $<\alpha=0,05$ disimpulkan bahwa ada hubungan yang bermakna antara olahraga dengan kejadian dismenore. Siswi yang kebiasaan olahraga kurang mempunyai peluang 14 kali mengalami dismenore dibandingkan dengan siswi yang kebiasaan olahraga baik (OR= 14,096).

\section{Analisis multivariat}

Analisis multivariat dilakukan untuk mengetahui faktor yang paling berpengaruh (Status gizi dan olahraga) terhadap kejadian dismenore pada siswi Madrasah Aliyah Negri 1 Kota Bengkulu . Uji yang digunakan adalah uji regresi logistik.
Tabel 3 Hasil Analisis Regresi Logistik Berganda pengaruh status gizi dan olahraga terhadap kejadian dismenora

\begin{tabular}{lccc}
\hline \multirow{2}{*}{ Variabel } & \multicolumn{3}{c}{ Nilai p regresi logistik } \\
\cline { 2 - 4 } & Tahap I & Tahap II & Keterangan \\
\hline Status gizi & 0,000 & 0,000 & Bermakna \\
Olahraga & 0,000 & 0,001 & Bermakna \\
Konstanta & 0,002 & 0,000 & Bermakna \\
\hline
\end{tabular}

Setelah masing-masing nilai $p$ diseleksi dengan metode enter, diperoleh bahwa ada hubungan yang paling bermakna antara status gizi siswi dengan kejadian dismenore ( $\rho=$ $0,001<\alpha=0,05)$.

\section{PEMBAHASAN}

\section{Hubungan Status Gizi Dengan Dismenore}

Berdasarkan hasil analisis univariat menunjukan bahwa dari 211 siswi hampir sebagian kecil $(42,7 \%)$ siswi yang status gizi tidak normal meliputi status gizi kurus $(38,9 \%)$, gemuk $(3,8 \%)$. Umumnya siswi yang mengalami status gizi tidak normal disebabkan oleh kebiasaan remaja mengkonsumsi makanan yang tidak seimbang dengan kecukupan yang diajurkan, hal ini berdampak terhadap pertumbuhan kesehatan reproduksinya.

Berdasarkan analisis bivariat didapatkan bahwa sebagian besar $(76,7 \%)$ siswi yang status gizi tidak normal mengalami dismenore. Hasil uji statistik diperoleh $\rho=0,000$ $<\alpha=0,05$, disimpulkan bahwa ada hubungan yang bermakna antara status gizi siswi dengan kejadian dismenore. Siswi yang status gizi tidak normal mempunyai peluang 4,2 kali mengalami dismenore dibandingkan dengan siswi status gizi normal $(\mathrm{OR}=4,216)$. Hasil analisis multivariat diperoleh bahwa status gizi merupakan factor yang dominan mempengaruhi kejadian dismenore disbandingkan faktor olahraga.

Hasil penelitian juga menemukan 53 siswi $(43,8 \%)$ dengan status gizi normal yang mengalami dismenore. Hal ini terjadi karena ada faktor primer yang memungkinkan terjadinya dismenore yaitu faktor kejiwaan, faktor konstitusi, faktor obstruksi kanalis servikalis, faktor endokrin, dan faktor alergi. 
Hasil penelitian ini sejalan dengan penelitian Ricky, dkk (2008) yang menyatakan bahwa hubungan antara status gizi dengan keluhan dismenore. Begitu juga dengan penelitian yang dilakukan Anastasia (2009) yang menyatakan status gizi akan mempengaruhi keadaan kesehatan remaja wanita terutama kesehatan reproduksinya. Semakin tinggi status gizi seseorang maka akan semakin rendah keluhan dismenore.

Diaz (1998) menyebutkan bahwa wanita yang mengalami kelebihan jaringan lemak didalam tubuh akan membentuk jumlah prostaglandin berlebih yang mengakibatkan peningkatan aktivitas uterus dan syaraf-syaraf terminal rangsangan nyeri sehingga menimbulkan tekanan pada intrauterin hingga $400 \mathrm{mmHg}$ dan menyebabkan kontraksi miometrium sehingga menimbulkan nyeri haid atau dismenore.

Kelebihan jaringan lemak dalam kandungan tubuh seseorang juga akan menyebabkan hiperplasia pembuluh darah (mendesak pembuluh darah oleh jaringan lemak) sehingga aliran darah terganggu pada organ reproduksi wanita dan dengan berat badan kurang, rendah lemak dan rendah asupan kalori akan menyebabkan penekanan pada hipotalamus-hipofisis-ovarium dan rendahnya konsentrasi hormon ovarium dalam siklus menstruasi sehingga hal ini dapat menimbulkan dismenore pada saat menstruasi (Okparasta, 2003).

\section{Hubungan Olahraga Dengan Dismenore}

Berdasarkan hasil analisis univariat menunjukan bahwa 211 siswi hampir sebagian kecil $(37,4 \%)$ siswi yang kebiasaan olahraga kurang meliputi kebiasaan olahraga cukup $(18,95 \%)$, buruk $(17,06 \%)$, sangat buruk $(1,42 \%)$. kebiasaan olahraga siswi kurang disebabkan kurangnya inisiatif dan minat siswi untuk melakukan kegiatan olahraga secara rutin. Raimah (2006) menyebutkan bahwa wanita yang rutin melakukan olahraga akan memperoleh kesehatan yang maksimal untuk tubuhnya. Olahraga yang teratur akan meningkatkan derajat kesehatan seseorang, terutama wanita seperti kesehatan reproduksi pada wanita akan terjaga sehingga terhindar dari masalah seperti PMS, dismenore, oligomenore, dan lain-lain.

Berdasarkan analisis univariat menunjukan hampir seluruh $(89,9 \%)$ siswi yang kebiasaan olahraga kurang mengalami dismenore. Hasil uji statistik diperoleh $\rho=0,000<$ $\alpha=0,05$ disimpulkan bahwa ada hubungan yang bermakna antara olahraga dengan kejadian dismenore. Siswi yang kebiasaan olahraga kurang mempunyai peluang 14 kali mengalami dismenore dibandingkan dengan siswi yang kebiasaan olahraga baik $(\mathrm{OR}=$ 14,096).

Hasil penelitian ini sejalan penelitian Maryana (2005) dan Dyana (2010) yang menyatakan ada hubungan antara frekuensi olahraga dengan kejadian dismenore. Tjokronegoro (2004) menyebutkan bahwa kejadian dismenore akan meningkat dengan kurangnya olahraga, sehingga ketika terjadi dismenore, oksigen tidak dapat tersalurkan ke pembuluh-pembuluh darah di organ reproduksi yang saat itu terjadi vasokonstriksi sehingga menyebabkan timbulnya rasa nyeri tetapi bila seseorang teratur melakukan olahraga, maka dia dapat menyediakan oksigen hampir 2 kali lipat per menit sehingga oksigen tersimpan ke pembuluh darah yang mengalami vasokonstriksi dan dapat mencegah timbulnya dismenore atau nyeri haid.

Berdasarkan hasil penelitian Yustianingsih (2004), dismenore lebih sedikit terjadi pada wanita yang berolahraga dibandingkan wanita yang tidak melakukan olahraga/senam membiasakan olahraga ringan dan aktivitas fisik secara teratur seperti jalan sehat, berlari, bersepeda, ataupun berenang pada saat sebelum dan selama haid, hal tersebut dapat membuat aliran darah pada otot sekitar rahim menjadi lancar, sehingga rasa nyeri dapat teratasi atau berkurang. Latihan ini sedikitnya 30-60 menit dengan frekuensi 3-5 kali seminggu. Olahraga yang teratur akan memberikan efek hormonal dalam penurunan insidensi dismenore. Hal ini disebabkan oleh peningkatnnya kadar endorpin yang bersirkulasi dan menjadi obat penenang alami yang diproduksi oleh otak dan sum-sum tulang belakang (Brian, J.S, 2003). 
Namun demikian, terdapat 51 siswi $(38,6 \%)$ kebiasaan olahraga baik mengalami dismenore. Hal ini terjadi karena ada faktor primer yang memungkinkan terjadinya dismenore yaitu faktor kejiwaan, faktor konstitusi, faktor obstruksi kanalis servikalis, faktor endokrin, dan faktor alergi.

\section{KESIMPULAN}

Hasil penelitian menyimpulkan bahwa Siswi Madrasah Aliyah Negeri 1 Kota Bengkulu Tahun 2012 bahwa sebagian besar siswi mengalami dismenore, hampir sebagian siswi status gizi tidak normal, dan hampir sebagian siswi dengan kebiasaan olahraga kurang. Ada hubungan status gizi dan olahraga dengan kejadian dismenore, sedangkan fak-

\section{DAFTAR RUJUKAN}

Admin. 2006. Nyeri Haid Pada Remaja. Diakses darihttp:///. Nyeri Haid Pada Remaja.com, July 2006.

Aganoff, J. A. (1994). Aerobic Exercise, Mood States, and Menstrual Cycle Symptoms. Faculty of Humanities and Social Sciences. Diakses dari http/www. epublications. Bond.edu.au/hss_pubs/37.co.id. Januari 1994.

Agustina, Kristina. 2010. Faktor-Faktor Yang Berhubungan Dengan Dismenore. Diakses dari httpllwww.materi dismenore/faktor-faktor-yangberhubungan-dengan_21.html. Juli 2010.

Almatsier, S., 2006. Penuntun Diet. Edisi Terbaru, PT Ikrar Mandiriabadi: Jakarta.

Anastasia, V.Y. (2009). Hubungan Status Gizi Dengan Keluhan Nyeri (dismenore) Saat Menstruasi Pertama (Menarche) Pada Siswi SLTPN 21 Surakarta. Diakses dari http/www.anastasiaveny.com. 11 Desember 2011.

Anurogo, Dito. 2008. Segala Sesuatu Tentang Dismenore. Diakses dari http://www.pewartakabarindonesia.blogspot.com. Januari 2008.

Arisman. 2008. Gizi Dalam Daur Kehidupan. EGC: Jakarta.

Baziad Ali, dkk. (1993). Endokrinologi Ginekologi. Edisi Pertama. KSER: Jakarta.

Dyana, N. Hubungan Dismenore dengan Olahraga Pada Remaja Usia 16-18 Tahun di SMA St. Thomas 1 medan. Diakses dari http://www. undip.com. Desember 2011.

Lefebvre, dkk. 2005. Primary Dysmenorrhea Consensus Guideline, No 169. Diakses dari tor yang paling dominan berpengaruh terhadap kejadian dismenore yaitu olahraga.

Hasil penelitian mengharapkan pihak institusi pendidikan terkait untuk mengembangkan sarana informasi yang berkaitan dengan kesehatan reproduksi seperti membentuk bimbingan konseling yang bergerak di-bidang Kesehatan Reproduksi Remaja (KRR) sehingga siswi disekolah tidak hanya mendapatkan pengetahuan dibidang akademis namun juga dapat menambah wawasan tentang kesehatan reproduksi serta dapat mengatasi setiap permasalah-permasalah kesehatan yang timbul terutama kesehatan reproduksinya seperti dimenore, PMS, oligomenore dan lain-lain pada dirinya melalui bimbingan tersebut.

http lwww. 169E-CPGDecember 2005.pdf .com. Desember 2005.

Locke, R. L. (1991). What Is The Effect Of Exercise On Primary Dysmenorrhea. The Paper Was Originally Published In The British Journal Of Sports Medicine 1991; 33: 227.

Manuaba, IBG. 1998. Ilmu Kebidanan, Penyakit Kandungan \& Keluarga Berencana Untuk Pendidikan Bidan. EGC: Jakarta.

McGowan, Mary P, 2007. Menjaga Kebugaran Jantung. PT Raja Grafindo Persada: Jakarta.

Novia, Ika, dkk. 2006. Faktor Resiko Yang Mempengaruhi Kejadian Dismenore Primer. The Indonesian Journal of Public Health, Vol 4 FK-UNAIR: Surabaya Hal 96-104.

Okparasta, 2003. Kesehatan Reproduksi Wanita. Diakses dari http:// wanitadandismenore. com. November 2003.

Qittun. 2008. Konsep dysmenorrhea. Diakses dari http:// Konsep-dismenorea.com. November 2008.

Sharkey, Brian J. 2003. Kebugaran Dan Kesehatan. PT Raja Grafindo Persada: Jakarta.

Sanya , A. L dan Cesilia (2007), M. D. Usia Menarche, Komsumsi Pangan, dan Status Gizi Anak Perempuan Sekolah Dasar di Bogor. Jurnal Gizi dan Pangan 2 (3): 26-35.

Singh Amita, dkk. 2008. Prevalence And Severity Of Dysmenorrhea, 389-397. Diakses dari httpllwww. Dysmenorrhea department of physiology.pdf.com. Juni 2008.

Supariasa dkk, 2001. Penilaian Status Gizi. EGC: Jakarta. 
Tjokonegoro, 2004. Olahraga dan Wanita. PT Dian Rakyat: Jakarta.
Wiknjosastro, H., 2005. Ilmu Kebidanan. Edisi Ketiga, Tridasa Printer: Jakarta 
